\title{
ALFABETIZAÇÃO E LETRAMENTO NO ENSINO FUNDAMENTAL
}

\author{
Jaciara Bispo Reis 1 \\ Marilia Gabriela Silva Borges ${ }^{2}$
}

\begin{abstract}
Resumo
Compreendendo que a alfabetização é um dos grandes desafios a ser superado, no âmbito educacional e que gera inúmeras reflexões este artigo propõe uma reflexão a partir dos dispositivos legais sobre a implantação do Ensino Fundamental de Nove Anos, as especificidades inerentes a concepção de criança, infância e adolescência. A metodologia para a obtenção de dados descritivos respalda-se na abordagem da pesquisa bibliográfica . Conclui-se, neste estudo, que através da (re) construção de estratégias pedagógicas que proporcionem o avanço do processo de Alfabetização e Letramento, pela mediação do profissional docente é possível assegurar a aprendizagem significativa da leitura e da escrita, por um processo lúdico, considerando os conhecimentos prévios do estudante, potencializando saberes e fazeres significativos que garanta a cada menino e menina do $1^{\underline{a}}$ ano, do ciclo inicial da alfabetização, o direito de aprender.
\end{abstract}

Palavras-chave: Alfabetização. Letramento. Aprendizagem.

\begin{abstract}
Understanding that literacy is one of the great challenges to be overcome, in the educational scope and that generates countless reflections, this article proposes a reflection from the legal provisions on the implementation of Teaching the specificities inherent to the conception of children, childhood and adolescence. The methodology for obtaining descriptive data is based on the bibliographic research approach. It is concluded, in this study, that through the (re) construction of pedagogical strategies that provide the advance of the Literacy and Literacy process, through the mediation of the teaching professional it is possible to ensure the significant learning of reading and writing, through a playful process, considering the student's prior knowledge, enhancing knowledge and meaningful actions that guarantee every boy and girl of the 1 st year of the initial literacy cycle, the right to learn.
\end{abstract}

Keywords: Literacy. Literacy. Learning.

Introdução

A alfabetização e o letramento possuem um vínculo entre si na construção da aprendizagem da leitura e da escrita e nesse processo existem implicações da avaliação formativa de modo que as estratégias específicas potencializam práticas de leituras e de escrita junto aos estudantes integrantes do ciclo inicial de alfabetização. Justifica-se a relevância desse trabalho em decorrência da realidade enfrentada pelos alfabetizadores, pela comunidade e pelas políticas públicas, evidenciadas nos resultados do processo da alfabetização escolar, apresentadas

\footnotetext{
${ }^{1}$ Mestra em Ciências da Educação pela FICS. Especialista em Coordenação e Supervisão Escolar pela UEFS-Universidade Estadual de Feira de Santana-Ba. Especialista em Alfabetização e letramento pela Faculdade Hélio Rocha. Graduada em Pedagogia pela UEFS-Universidade Estadual de Feira de Santana-Ba. Docente da Rede Municipal de Ensino.Email:jacireis11@outlook.com

2 Mestra em Ciências da Educação, pela Faculdade Interamericana de Ciências Sociais FICS.Especialista em Psicopedagogia Clínica e Institucional pela Segmento. Licenciatura Plena em Pedagogia pela UEFS- Universidade Estadual de Feira de Santana. Professora da Rede MunicipalSanto Amaro Ba. Email: gabriela.borges19@ yahoo.com.br
} 
pelas avaliações nacionais, estaduais e municipais (MORAIS, 2019). Tal situação coloca o educador diante da necessidade de refletir sobre as estratégias pedagógicas que são dinamizadas nas práticas que direcionam a aprendizagem da leitura e da escrita.

$\mathrm{Na}$ organização estrutural do Ensino Fundamental de nove anos em ciclos de aprendizagem existe um paralelo diferencial entre a progressão da aprendizagem e a progressão continuada. Mas é necessário atentar-se para que não se configure em progressão automática, evitando que os estudantes tenham suas trajetórias escolares retardadas ou interrompidas ou que sejam promovidos para os anos de escolarização subsequente sem consolidar os saberes essenciais de leitura, escrita compreensão e produção textual.

A interação com o meio social no processo da alfabetização e linguagem favorece a aprendizagem, uma vez que as crianças se tornam atores sociais que interagem com os signos e símbolos construídos socialmente.

\section{Refletindo Sobre a Aprendizagem e o Ensino da Alfabetização}

O conceito etimológico do termo alfabetização quer dizer processo de aquisição do código escrito, mas é também um processo de compreensão e expressão de significados. Portanto a alfabetização não é meramente a apropriação do código escrito: codificar e decodificar, não se reduz apenas a um processo de associação entre grafemas (letra) e fonemas (sons). Nesse viés, pode-se explicar essa relação ao afirmar que:

Ensinar a ler e escrever é um desafio que transcende amplamente a alfabetização em sentido estrito. O desafio que a escola enfrenta hoje é o de incorporar todos os alunos à cultura do escrito, é o de consegui que todos exalunos cheguem a ser membros da comunidade de leitores e escritores(LERNER, 2007, p.17).

Partindo desses pressupostos, entende-se que, o sistema de escrita alfabética na realidade é um sistema notacional. Faz-se necessário, portanto, que o (a) estudante para ler e escrever compreenda como funciona esse sistema: descubra o que a escrita representa e como a escrita representa. Descobrir e compreender que há uma relação entre os sons / fala e a escrita, que isso não se aprende por memorização e fixação, mas que é preciso compreensão de como o sistema de escrita se organiza (Id., 2002). Isso é crucial para que a alfabetização se consolide.

Nesse contexto, o alfabetizando necessita compreender que a escrita representa os sons da fala, que os grafemas (as letras) representam os fonemas e pode ser representado pela escrita e também, compreender como a escrita 
representa os grafemas (as letras) e se organizam nas palavras para representar os fonemas (os sons da fala).

Para que os alunos compreendam o que e como a escrita representa, entendendo como a relação fonema - grafema funciona, no sistema alfabético, é preciso a partir do trabalho sistemático com os diversos gêneros textuais possibilitar para o (a) estudante a realização de atividades de análise fonológica e estrutural, das unidades linguísticas, como reflexão metalinguística, isto é, pensar sobre a escrita, conforme elucida o caderno do Pacto Nacional pela Alfabetização na Idade Certa $(\mathrm{PNAIC})^{3}$, ao citar que:

[...] as habilidades de consciência fonológicas são necessárias para o aprendiz entrar na etapa de fonetização da escrita, que inclui níveis silábico, silábico- alfabético e alfabético. Reconhecendo que a consciência fonológica é uma condição necessária, mas não suficiente para criança se alfabetizar, consideramos essencial criar situações por meio das quais nossos alunos possam refletir sobre as formas orais e escritas das palavras. Elas envolvem as capacidades de partir palavras em silabas, comparar palavras quanto ao tamanho, e comparar palavras quanto às semelhanças sonoras de suas silabas, rimas ou fonemas iniciais (BRASIL, 2012, p.29).

Percebe-se assim, que para a aquisição da língua escrita, os alunos precisam entender como representar os fonemas, em grafemas, já que não há correspondência unívoca entre letras e fonemas. É importante ficar claro que a aquisição da língua escrita, é principalmente, a compreensão do que e como a escrita é representada.

Vale salientar a aquisição da escrita não é apenas a apropriação de um código. As funções da escrita mostram a complexidade da língua, que está associada a um conjunto cultural mais amplo. Nessa lógica, a visão da escrita apenas como notação da oralidade é uma visão reducionista da escrita. Isso não quer dizer que a oralidade não seja importante, visto que as práticas de oralidade são fundamentais no ciclo de Alfabetização. Nesse intento, salienta-se que:

[...] tomando sempre a oralidade como ponto de partida, [...] procurava levar o educando a considerar diversas realidades, fazendo com que assumisse um papel ativo, livre e criador na sua própria aquisição da linguagem escrita. Agente dos processos de alfabetização e letramento e desafiado a refletir a cada momento, sobre suas práticas, o aluno deixa de ser um mero receptáculo da aprendizagem e da cultura de sua comunidade (FRANCHI, 2012, p.9)

Saliento, corroborando com as ideias da autora, que a práxis pedagógica, desenvolvida com essa finalidade, exige variadas estratégias metodológicas, em consideração a realidade sociocultural dos alunos e o contexto da escola. Nessa

\footnotetext{
${ }^{3}$ Programa que busca diminuir os índices de analfabetismo no país.
} 
perspectiva, a alfabetização deve se pautar no que para as crianças a aprendizagem da língua escrita pode lhes apresentar como saber novo em relação ao conhecimento por elas construídos no uso que até então faziam da linguagem oral em seu cotidiano, se reverberando em práticas alfabetizadoras pela mediação feita pelo(a)professor(a) no processo de ensino e aprendizagem.

As características peculiares de cada grupo de criança suscitam formas diferenciadas de ação pedagógica durante os processos de alfabetização e letramento, sendo importante refletirmos sobre a relação entre esses dois conceitos.

\section{Tecituras Entre Alfabetização e Letramento}

Atualmente, podem-se perceber novas facetas do fenômeno da alfabetização que modificaram o olhar dos educadores em relação a este fenômeno que é social, político, pedagógico, psicológico, antropológico, histórico e linguístico.

Nesse sentido, para cada dimensão dessas facetas que é descoberta, tenta-se transformar práticas pedagógicas anteriores, especialmente, quando busca a cada dia (re) dimensionar o fazer pedagógico, nas classes do Ciclo da Alfabetização, onde se almeja formar alunos que saibam ler e escrever; que se utilizem desse conhecimento de forma construtiva e significativa e que participe do universo da cultura escrita, incorporando novas práticas envolvidas no letramento. Elucidando esse entendimento, pode-se definir que o termo letramento é um estado ou condição "de quem não apenas sabe ler e escrever, mas cultiva as práticas sociais que usam a escrita e alfabetização como o ato de ensinar e aprender a ler e escrever" (SOARES, 2000, p.47).

A autora salienta que embora conceitualmente distintos na prática educativa, ocorrem como processo simultâneo, que se intercomplementam no ato de ensinar e aprender. Pode-se evidenciar que o conceito de letramento abrange o conceito de alfabetização, mas que a alfabetização supõe estratégias específicas para ensinar a ler e escrever.

Nessa perspectiva, o conceito de letramento abre um horizonte de possibilidades pedagógicas, ajuda a compreender os contextos sociais e sua relação com as práticas escolares e possibilita investigar a relação entre práticas sociais e a aprendizagem da leitura e da escrita.

Baseando-se nesse entendimento, é primordial repensar o papel da escola como espaço onde as práticas de letramento se estabelecem e se definem, através 
dos usos sociais, levando em consideração que a vivência e participação em atos de letramento podem ampliar as possibilidades de aprendizagem no ciclo de alfabetização e mais especificamente nas turmas, do $1^{\circ}$ ano, do Ensino Fundamental Anos Iniciais.

Diante do exposto, pode-se compreender que no Ensino Fundamental de Nove Anos a ação pedagógica necessita ser redimensionada no que concerne a forma de avaliar a aprendizagem do (a) estudante, uma vez que a criança de seis anos de idade, está iniciando o desenvolvimento de um conjunto de conhecimentos e capacidades, considerados fundamentais para o processo de alfabetização e letramento.

Nessa perspectiva, a Alfabetização e o Letramento são processos que se interrelacionam, complementando-se como práticas indissociáveis no processo de ensino e aprendizagem. E nesse sentido, se são processos, portanto não tem fim. Daí, em todas as situações educativas, a escola deve promover a interação do (a) estudante com o meio no qual está inserido, (re) pensando assim a sua finalidade, pois:

\begin{abstract}
O verdadeiro papel da escola, que é alfabetizar dando ao aluno a possibilidade de descobrir o mundo em que está inserido, e do qual é parte primordial, tendo em mente que desse mundo que deverão sair todos saberes e é a ele que esses mesmos saberes retornarão reelaborados. É, portanto em mundo assim vivo, dinâmico, que devemos trazer para as nossas atividades de alfabetização (ALMEIDA, 2008, p. 6).
\end{abstract}

Considerando essa abordagem, é relevante destacar que antes mesmo de se alfabetizar, de ser ensinado o código da escrita, habilidades da leitura e da escrita, o sujeito já lê a vida, a realidade, o contexto no qual está inserido, lê as figuras, os objetos, os signos, enfim lê o mundo. Cabe-nos elucidar, nessa perspectiva, que "a leitura do mundo precede a da palavra" (FREIRE, 1996, p.11) e que é por meio de experiência vivida, que se desenvolve a curiosidade para a leitura e escrita.

Nesse processo, é relevante que o aprendizado da escrita e da leitura oriente sempre para o que seja ler e escrever, pois nenhum processo ou método de alfabetização será eficaz se retirar o valor da escrita e da leitura na prática social contemporânea (FRANCHI, 2012).

Partindo dessa perspectiva, só o processo de alfabetizar (domínio do código escrito) não é suficiente para obter-se ascensão social e cultural, sendo, portanto, essencial que o processo de alfabetização ocorra numa perspectiva de letramento. Desse modo, faz-se necessário estar atento (a) em reconhecer que: 
sensibilidade e a atenção das crianças para o material de fato relevante e preparar a situação em que elas possam participar ativamente desse trabalho de construção de hipóteses (Ibid., p. 206).

Baseados nesse contexto, o (a) professor (a), enquanto mediador da aprendizagem deverá fazer as intervenções necessárias, acompanhar e explorar os conhecimentos já adquiridos pelos (as) estudantes, apresentar desafios, estimular a participação ativa em situações que despertem o gosto pela leitura e a escrita, ou seja, que (re) construam os conhecimentos como protagonista de todo processo.

Nesse intento, corrobora-se com a ideia de que "há necessidade de romper com a pedagogia frontal, ou seja, as mesmas lições e exercícios para todos e criar uma organização de trabalho e dos dispositivos didáticos" (PERRENOUD, 1999, p.26), sendo relevante refletir, portanto, que em uma classe há diversos alunos, com variados níveis de desenvolvimento, conhecimentos prévios singulares, diferentes saberes e fazeres e diferentes maneiras de aprender.

A escola deve desenvolver um trabalho que prime pela aprendizagem significativa, com conteúdos significativos e um processo avaliativo formativo, cuja avaliação diagnóstica e processual, favoreça a constatação de avanços e necessidades, propicie a observação e o desenvolvimento das expectativas de aprendizagem essenciais em cada ano de escolarização. Enfim, aponte caminhos para que as intervenções pedagógicas sejam realizadas, junto a todos (as) os (as) estudantes com igualdade de oportunidades e direitos.

Para que tal finalidade se efetive, o processo de avaliação desenvolvido junto às crianças de seis, sete e oito anos de idade, integrantes do Ciclo inicial da alfabetização, merece um olhar sensível, pois estando na infância, caracterizada por especificidades, os espaços, tempos e ritmos de aprendizagem devem ser respeitados.

As unidades escolares, com papel preponderante nesse processo, deverão refletir (re) avaliar e (re) configurar a sistemática de avaliação aplicável ao conjunto dos anos de escolarização, no ${ }^{\circ}$ Ciclo da Infância.

\section{Alfabetização e Linguagem da Criança de 6 Anos do Ensino Fundamental Anos Iniciais}

O ingresso das crianças de 6 anos no Ensino Fundamental, em função da Lei 
$\mathrm{n}^{\circ} 11.114$ de 16 de maio de 2005 que estabeleceu como obrigatória a matricula das crianças de 6 (seis) anos de idade no Ensino Fundamental, pela alteração dos artigos $6^{\circ}, 32$ e 87 da Lei de Diretrizes e Bases da Educação Nacional (Lei n 9.394/1996), pressupõe uma nova diretriz de trabalho para o primeiro ano do Ensino Fundamental.

Partindo desse pressuposto os processos educativos precisam ser adequados a faixa etária das crianças ingressantes para que a transição da Educação Infantil para o Ensino Fundamental aconteça sem rupturas traumáticas, num processo natural, sistêmico e complementar. Nesse intuito, a Resolução do Conselho Estadual de Educação (CEE) $)^{4} \mathrm{~N}^{\circ} 60 / 2007$ no Art. $2^{\circ}$, parágrafo $1^{\circ}$, define que:

Para organizar o trabalho pedagógico no $1^{\circ}$ ano (6 anos),será crucial considerar a infância em suas dimensões física, cognitiva e psicossocial e para o planejamento das atividades é imprescindível observar :o princípio da ludicidade; os pressupostos do processo de aquisição da leitura e da escrita, na perspectiva do letramento; do raciocínio lógico; e das formas de convivência social, inerentes à infância (BRASIL, 2007,[s/p]).

Essa nova diretriz de trabalho requer um olhar sensível para a superação de alguns novos desafios, onde as ações pedagógicas priorizem o processo de desenvolvimento da aprendizagem (do educador e do educando), integrando, dentro de uma visão de totalidade, os vários níveis de conhecimento, expressão e (re) significação dos conteúdos escolares. Um desses desafios, refere-se a compreensão sobre o ensino da língua escrita sendo relevante ressaltar que:

\begin{abstract}
A língua é um sistema que se estrutura no uso e para o uso, escrito e falado, sempre contextualizado. No entanto a condição básica para o uso escrito da língua, que é a apropriação do sistema alfabético, envolve, da parte dos alunos, aprendizados muito específicos, independentes do contexto de uso, relativos aos componentes do sistema fonológico da língua e ás suas interrelações (BRASIL, 2007,[s/p]).
\end{abstract}

É essencial, construir uma prática educativa que coloque a criança como centro do processo e que leve em consideração as diferentes dimensões de sua formação, propiciando o desenvolvimento da Leitura e da Linguagem escrita, como uma garantia de direito á Educação.

Desse modo é fundamental, colocar a criança frente aos novos conhecimentos e desafios intelectuais, como protagonista do seu processo de aprendizagem, por meio da interação com as práticas sociais de comunicação. Vale salientar, que essas as crianças já imersas socialmente na cultura escrita, antes mesmo de ingressar na

\footnotetext{
${ }^{4}$ Responsável em subsidiar e acompanhar a execução do Plano Estadual de Educação
} 
escola, deve ter validado, no âmbito das práticas pedagógicas, esse contato, para favorecer a apropriação da cultura escolar, tornando a instituição educativa, ela mesma expressão ou não do direito à educação. Isso significa dizer que:

\begin{abstract}
O dia-a-dia em de aula foi me mostrando que a linguagem, trabalhada no âmbito da alfabetização e do letramento, antes de ser usada somente para comunicação, é parte importante; da elaboração do conhecimento; antes de ser mensagem, contribui para a construção do pensamento do aluno; e antes de ser veículo de seus sentimentos, idéias, emoções, aspirações, a linguagem foi um processo criador por meio do qual as crianças organizavam e informavam suas experiências. Enfim, a aprendizagem da linguagem escrita não foi somente o instrumento de inserção justa do aluno entre os outros, foi também um instrumento da intervenção e da dialética entre a professora (eu) e cada uma das crianças, entre elas e o mundo (FRANCHI, 2012, p.9).
\end{abstract}

A escola deve ser o principal gerador de ações sistemáticas que fazem uso da leitura e da escrita, como agentes facilitadores de práticas sociais dentro e fora do ambiente escolar, de modo que por meio da aquisição a leitura e da escrita, ocorra o desenvolvimento de indivíduos alfabetizados e letrados, que se apropriem do sistema alfabético através de situações de aprendizagem sequenciadas, articuladas e contextualizadas.

Neste contexto a infância é reconhecida como uma construção social inserida em um contexto do qual as crianças participam efetivamente como atores sociais de pleno direito, devemos, igualmente, considerá-las sujeitos capazes de interagir com os signos e símbolos construídos socialmente, bem como de construir novos signos e símbolos a partir dessa interação. O processo educativo não envolve apenas técnicas, mas deve acompanhar uma busca de soluções para as diversas situações que se apresentam, articulando saberes e competências (PERRENOUD, 1999).

Partindo desses pressupostos, busca-se favorecer o ensino e a aprendizagem dos (as) estudantes, promovendo a avaliação formativa, com o acompanhamento e desenvolvimento de intervenções pedagógicas, a partir de metodologias ativas, que fomente a aprendizagem significativa dos alunos, cuja interação entre os atores curriculantes, assume um papel preponderante.

A apropriação do Sistema Alfabético de Escrita acontece por meio de atividades lúdicas e reflexivas, com participação em situações de leitura e produção de textos, ampliando as referências culturais das crianças nas diferentes áreas do conhecimento. Para a consolidação do sistema de Escrita Alfabética e o sucesso na alfabetização, faz-se necessário a transformação da escola em 'ambiente alfabetizador', rico em estímulos que provoquem atos de leitura e escrita, permitam 
compreender o funcionamento da língua escrita, possibilitem a apropriação de seu uso social, e forneçam elementos que desafiam o sujeito a pensar sobre a língua escrita.

A alfabetização é, sem dúvida, uma das prioridades nacionais na contemporaneidade, pois o professor alfabetizador tem a função de auxiliar na formação, dos alunos, para o bom exercício da cidadania, ciente de que é preciso ter clareza do que ensina e como ensina. O professor é o mediador e não um reprodutor de métodos que objetivem apenas o domínio de um código linguístico. É preciso que o(a)docente compreenda sobre qual concepção de alfabetização está subjacente à sua prática para que ensine mais e melhor.

No contexto da Alfabetização, vale a pena ressaltar a necessidade do professor ser um pesquisador da sua prática. É preciso que o professor investigue e deixe emergir em sala de aula as ideias e conceitos próprios das crianças acerca dos diferentes saberes trabalhados, para assim desafiá-las a avançar em seus conceitos, no que se refere ao Sistema de Escrita Alfabética (SEA).

O professor não precisa ter todas as respostas. Ele é na verdade um pesquisador que vai buscando nas ações didáticas, ampliar também seus saberes e fazeres, junto com suas crianças. Como mediador nesse processo de construção, é alguém que questiona que organiza o grupo em torno das necessidades e curiosidades que surgem, que vai indicando caminhos, desdobramentos e desenvolvimentos, a partir das ideias e saberes infantis, tornando a educação uma experiência rica e significativa para os (as) estudantes.

Nessa perspectiva é crucial para a aprendizagem da leitura e da escrita dos (as) estudantes, em fase de alfabetização, que o (a) professor (a) para além das constatações das necessidades de aprendizagem, evidenciadas nas atividades iniciais, compreenda que a criança ao pensar sobre a escrita, formula hipóteses, tentativas de sistematização sobre a natureza da linguagem.

Nessa abordagem, Ferreiro (1991, p.31) ressalta que:

Em linguagem oral permitimos à criança que se engane ao produzir, tanto quanto ao interpretar, e que aprenda através de suas tentativas para falar e para entender a fala dos outros. Em língua escrita todas as metodologias tradicionais penalizam continuamente o erro, supondo que só se aprende através da reprodução correta, e que é melhor não tentar escrever, nem ler, se não está em condições de evitar erro. A consequência é inevitável é a inibição: as crianças não tentam ler nem escrever e, portanto, não aprendem. 
É imprescindível, que essas tentativas não sejam consideradas como erro e, sim vistas como uma construção inerente do processo de aquisição da leitura e da escrita.

Na língua oral não se aprende um fonema nem uma sílaba e nem uma palavra
por vez. As palavras são aprendidas, são desaprendidas, são definidas e
redefinidas continuamente. Não Há um processo cumulativo simples unidade
por unidade, mas organização, desestruturação e reestruturação contínua.
As crianças podem ir sistematizando o que aprendem (na aprendizagem da
linguagem e em todos os domínios do conhecimento), põem à prova a
organização conseguida através de atos efetivos de utilização do
conhecimento adquirido, e reestruturam quando descobrem que a
organização anterior é incompatível com os dados da experiência
(FERREIRO,1991, p.31).

À luz dessas considerações, corroboro com a afirmativa de Franchi (2012, p.22) de que:

O trabalho do professor, então não é o de contrariar as hipóteses iniciais insuficientes, mas oferecer, gradualmente, o material de fato necessário e as condições de trabalho satisfatórias para a construção, pelas próprias crianças, dessas hipóteses sucessivas (FRANCHI, 2012, p.22).

Baseado nesses aspectos destaca-se a importância da mediação do (a) professor (a) em favorecer a interação dos (as) estudantes com seus pares, com o contexto que o circunda e com o objeto de conhecimento, que nessa situação específica, é a aquisição da leitura e a escrita.

A partir desses pressupostos, é crucial para o (a) alfabetizador (a) a percepção de que a criança do $1^{\circ}$ ano do ciclo inicial de alfabetização tem "[...] diferentes motivações e níveis diferenciados de conceptualização para o aprendizado da leitura e da escrita [...] e estes devem ser considerados antes de iniciar o processo" (FRANCHI, 2012, pp.77-78).

À luz dessas considerações fica evidente que:

A escola é, assim, um lugar social onde o contato com o sistema de escrita e com a ciência enquanto modalidade de construção de conhecimento se dá de forma sistemática e intensa, potencializando os efeitos desses outros aspectos culturais sobre os modos de pensamento. Além disso, na escola o conhecimento em si é objeto privilegiado da ação dos sujeitos envolvidos, dependentemente das ligações desse conhecimento com a vida imediata e com a experiência concreta dos sujeitos (KLEIMAN, 1995, p.156).

Desse modo o desenvolvimento das ações didático-pedagógicas na escola, não se restringe à sala de aula, mas com foco na formação humana, o (a) professor (a) desenvolve as tarefas educativas vinculada com a vida em sociedade (LIBÂNEO, 2013), com foco na articulação teoria e prática para potencializar o ensino e garantir aprendizagem. 
Em suma, vale lembrar a afirmação de Kramer, "a educação, uma prática social, inclui o conhecimento científico, a arte e a vida cotidiana" (KRAMER, 2007, p.19). Isto implica conceber a educação, e particularmente, a alfabetização como sendo parte dos direitos de aprendizagem de todas as crianças, ao mesmo tempo em que partimos do princípio de que a educação se constitui como um ato político e de conhecimento (FREIRE, 1979).

Nesse intento, Freire contextualiza que, "a leitura da palavra deve ser inserida na compreensão da transformação do mundo" (Ibid,1979), ou seja, ao se viabilizar a leitura da palavra, o educador estaria possibilitando, ao mesmo tempo, ao educando ler o mundo.

\section{Considerações Finais}

É fundamental, entender o processo de desenvolvimento da criança, de ensino e de aprendizagem da leitura e da escrita e suas implicações no desafio da reflexão e da (re)avaliação do fazer diário, como busca de compreender na fusão estabelecida entre a teoria e a prática, os entraves enfrentados nesta dinâmica e buscar fortalecer e/ou (re)construir novas estratégias pedagógicas que proporcionem o avanço do processo de Alfabetização e Letramento, assegurando a aprendizagem significativa dos estudantes. Este estudo se reverbera nas comprovações da efetividade do desenvolvimento de estratégias interventivas adequadas para garantir a aprendizagem da leitura e da escrita

Para a consolidação do sistema de Escrita Alfabética e o sucesso na alfabetização, faz-se necessário a transformação da escola em "ambiente alfabetizador", rico em estímulos que provoquem atos de leitura e escrita, permitam compreender o funcionamento da língua escrita, possibilitem a apropriação de seu uso social, e forneçam elementos que desafiam, o sujeito, a pensar .No que concerne às práticas para apropriação do sistema de escrita alfabética, percebeu-se a predominância de atividades estruturantes e alimentadoras, trabalhadas a partir de gêneros textuais diversos, especificamente, parlendas, trava-línguas, cantigas, adivinhas, receitas, contos, etc.

Destaca-se, também, neste contexto, a análise estrutural e fonológica de frases, palavras, silabas e letras das palavras, estabelecendo relação entre fonemagrafema, identificação, contagem de letras, silabas, por meio da interpretação dos textos apresentados. 
É imprescindível para o professor(a) no seu fazer diário, o exercício da reflexão como propulsora de desconstrução da curiosidade ingênua tornando-se curiosidade epistemológica onde a crítica reflexiva não só inaugura o olhar necessário para sua própria prática como ,também, transforma as atividades cotidianas da sala de aula com o rigor científico merecido, as questões de aprendizagens dos (as) estudantes em objeto de pesquisa.

A relação professor e aluno precisa ser uma relação dialógica, onde os estudantes tenham oportunidade de serem escutados, principalmente, no que tange ao processo de aprendizagem. O professor(a), nesse contexto, é aquele mediador que deve sempre se voltar para onde o aluno se encontra, no processo de aprendizagem e a partir deste ponto, organizar sistematicamente o trabalho, configurando-o em estratégias de intervenção pedagógica.

No tocante a concepção de ensino e aprendizagem do professor e o nível de conhecimento profissional de que dispõe sobre o processo de alfabetização, faz-se necessário que para além da articulação teoria e prática ,a formação continuada, fomente a compreensão dos processos de ensino e aprendizagem, de modo que o(a) professor(a) possa planejar as aulas previamente, e possa intervir nas situações de aprendizagens a partir das necessidades evidenciadas, sinta-se parte integrante do processo de alfabetização; amplie o leque de possibilidade de ensino e de aprendizagem; redimensione o fazer pedagógico; reflita e aja sobre a realidade para que as aprendizagens se consolidem.

\section{Referenciais}

ALMEIDA, P. N. d. Educação lúdica: técnicas e jogos pedagógicos. São Paulo, SP: Loyola, 2008.

BRASIL. Ministério da Educação. Programa Pacto Nacional pela Alfabetização na Idade Certa: a aprendizagem do sistema de escrita alfabética:ano1:unidade3.Brasília:MEC, SEB,2012

BRASIL. Comitê Nacional de Educação em Direitos Humanos. Plano Nacional de Educação. Ministério da Educação, Ministério da Justiça,. Brasília: UNESCO, 2007. FRANCHI, E. Pedagogia do Alfabetizar Letrando: da Oralidade à escrita,9 edição.São Paulo:Cortez,2012.

FREIRE, P. Pedagogia da Autonomia, 5a ed., São Paulo: Paz e Terra. 1996

FERREIRO, E. Reflexões sobre alfabetização. Editora Cortez. São Paulo. 1991.

KLEIMAN, A. Os signiicados do letramento: uma nova perspectiva sobre a prática social da escrita. Campinas: Mercado da Letras, 1995.

LERNER, D. Ler e escrever na escola: 0 real, o possível e o necessário. São Paulo: Armed, 2007.

LIBÂNEO,J.C.Didática. 2ª Edição, São Paulo :Cortez ,2013 
MORAIS,A G de.Consciencia fonológica na educação infantil e no ciclo de alfabetização.1 $1^{a}$ edição:Autêntica editora,2019.

PERRENOUD.P. Pedagogia Diferenciada. Das Intenções à Ação. Porto Alegre: Artmed Editora, 1999

SOARES, M. Alfabetização e Letramento: caminhos e descaminhos. Disponível em http://www.acervodigital.unesp.br/bitstream/123456789/40142/1/01d16t07.pdf 